This item was submitted to Loughborough's Research Repository by the author.

Items in Figshare are protected by copyright, with all rights reserved, unless otherwise indicated.

\title{
The effects of outlet geometry on automotive demister performance
}

PLEASE CITE THE PUBLISHED VERSION

http://dx.doi.org/10.4271/2000-01-1277

PUBLISHER

(C) SAE International

VERSION

VoR (Version of Record)

LICENCE

CC BY-NC-ND 4.0

REPOSITORY RECORD

Cole, Jonathan, Martin A. Passmore, and Eddie Rice. 2010. "The Effects of Outlet Geometry on Automotive Demister Performance”. figshare. https://hdl.handle.net/2134/6708. 


\section{The Effects of Outlet Geometry on Automotive Demister Performance}

Jonathan Cole and Martin Passmore

Loughborough Univ.

Eddie Rice

Visteon Automotive Systems 
The appearance of this ISSN code at the bottom of this page indicates SAE'S consent that copies of the paper may be made for personal or internal use of specific clients. This consent is given on the condition, however, that the copier pay a $\$ 7.00$ per article copy fee through the Copyright Clearance Center, Inc. Operations Center, 222 Rosewood Drive, Danvers, MA 01923 for copying beyond that permitted by Sections 107 or 108 of the U.S. Copyright Law. This consent does not extend to other kinds of copying such as copying for general distribution, for advertising or promotional purposes, for creating new collective works, or for resale.

SAE routinely stocks printed papers for a period of three years following date of publication. Direct your orders to SAE Customer Sales and Satisfaction Department.

Quantity reprint rates can be obtained from the Customer Sales and Satisfaction Department.

To request permission to reprint a technical paper or permission to use copyrighted SAE publications in other works, contact the SAE Publications Group.

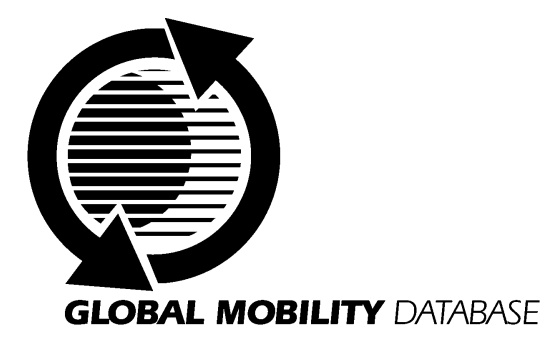

All SAE papers, standards, and selected books are abstracted and indexed in the Global Mobility Database

No part of this publication may be reproduced in any form, in an electronic retrieval system or otherwise, without the prior written permission of the publisher.

ISSN 0148-7191

Copyright $\odot 2000$ Society of Automotive Engineers, Inc.

Positions and opinions advanced in this paper are those of the author(s) and not necessarily those of SAE. The author is solely responsible for the content of the paper. A process is available by which discussions will be printed with the paper if it is published in SAE Transactions. For permission to publish this paper in full or in part, contact the SAE Publications Group.

Persons wishing to submit papers to be considered for presentation or publication through SAE should send the manuscript or a 300 word abstract of a proposed manuscript to: Secretary, Engineering Meetings Board, SAE.

\section{Printed in USA}




\title{
The Effects of Outlet Geometry on Automotive Demister Performance
}

\author{
Jonathan Cole and Martin Passmore \\ Loughborough Univ. \\ Eddie Rice \\ Visteon Automotive Systems
}

Copyright (@ 2000 Society of Automotive Engineers, Inc.

\begin{abstract}
The established method of clearing a misted car windshield or of maintaining a clear view under misting conditions is through the application of an air supply via jet outlets in the instrument panel. The ability of such arrangements to perform adequately is a function of the prevailing environmental conditions, the vehicle speed, the condition of the demist air source and the geometry and arrangement of the jet outlets.
\end{abstract}

This paper presents experimental data obtained in a purpose built environmental chamber designed to accommodate simple rectangular jets impinging on a misted glass surface. The facility consists of three conditioned air sources applied to a test chamber designed to represent the external, internal and demist air flows. Mist conditions on the glass surface are determined using a novel technique employing a CCD camera acquiring grey scale images which are digitally analysed to generate mist detection, grading and clearing contour data. The test facility and mist analysis techniques are described.

Transient jet performance is investigated in a parametric study that addresses the effects of jet aspect ratio, offset, impingement angle and mean volume flow rate on clearing performance. Results are presented in terms of parameters derived from the images recorded during the clearing process. These parameters include rate of clearing terms, breakthrough time and location of clearing centre relative to geometric impingement point.

Steady state performance is presented for a number of representative geometries by examining the size of the clear area for a range of interior humidity levels.

\section{INTRODUCTION}

Motor vehicles are sold and used throughout the World and are subject to a wide range of ambient conditions. In both warm and cool climates, specific conditions can cause water condensation on the interior surfaces of the passenger compartment glass; systems are therefore required to evaporate and remove this hindrance to the driver and passengers' view.

For many years, air sources heated by engine coolant have been used to maintain a clear view and they have generally proved successful, while being relatively cheap to implement. However, public expectations have risen and these systems are often considered to give inadequate results, both with respect to the rate of clearing and to the coverage across the glass surface. Alternative methods incorporating heating elements within the glass are very effective but are expensive and can have a high electrical power requirement [1][2]. As a consequence, the need for improvements to the design and operation of air based demisting systems remains.

This paper presents work from an ongoing study into automotive glass demisting, which has covered all aspects from point of mist initiation on the glass surface to the effects of surface contamination on demister performance. Work reported here highlights the effects of jet geometry on actual demist rates and position of demist areas on the glass surface, using greyscale imaging techniques and controlled environmental conditions.

\section{EXPERIMENTAL FACILITY}

Experimental research addressing demisting air flows have used actual car interiors [3][4][5] or models for use with flow visualization [6]. Related research with impinging fluid flows or wall jets have been conducted on wind tunnel walls [7] or with custom built calorimetered heat transfer surfaces [8]. Surface temperatures have been calculated locally using thermochromic paint [9] or infra-red thermography [10], or area averaged using highly accurate heat balancing of heat exchanging fluids [11]. In this work, the demist process is studied by direcly recording the distortion caused by the presence of surface condensation on a glass surface as heat is exchanged from air on one side of the glass to air on the other, as in the real case. 
Copyright $\odot 2000$ SAE International. This paper-is posted on this site with permission from SAE International, and is for viewing only.

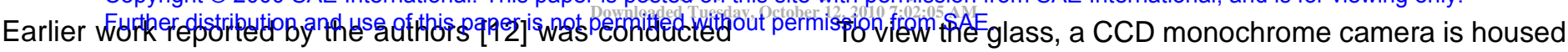
in a 1-D flow facility, where all the air on the interior side of the glass was exchanged during demisting. This simple facility provided useful corroborative data for derivation of a 1-D model to predict conditions under which misting initiates and analyse the sensitivity of the transient demisting case to changes in environmental conditions, such as demist air temperature.

To examine the effects of demist jet geometry required a more sophisticated test section, where 3-D flow fields could be produced, controlled and analysed. Figure 1 presents a horizontal section through the new facility. The test section is supplied by 3 closed-loop air circuits. Each passes through a separate air conditioning unit and fan to control the temperature, humidity and flow velocity. Exterior air passes through a contracting elbow upstream of the glass and along a narrow duct between the glass and a light box (3), from (1) to (2) in Figure 1.

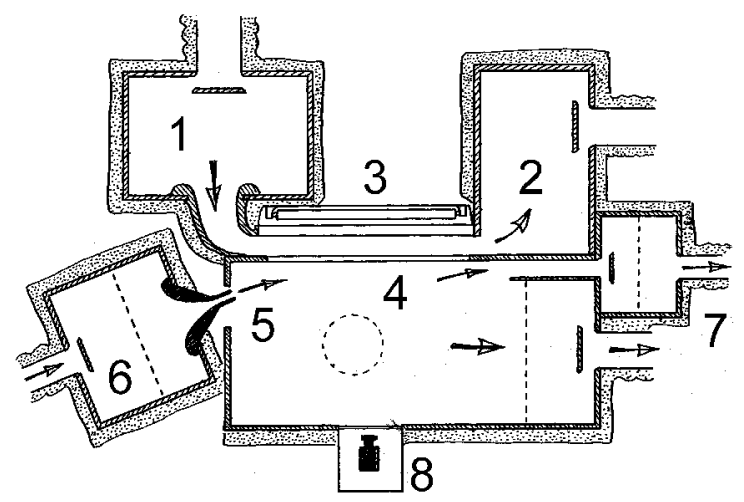

Figure 1. Horizontal section through the 3-D test section

Interior air enters from the top and bottom of the test section, before turning through $90^{\circ}$ across the glass surface (4) and exits through the right hand wall. Flow conditioning at both inlets ensures fluid spread throughout the volume and provide slow-moving conditioning flow across the glass. This circuit is largely designed to condition the glass surface to a misted state.

Demist air circulates outside the test section through a bypass pipe, with only a small bleed taken downstream of the fan to feed the test section demist jet (from 6 to 5). Approximately $10 \%$ of the flow in this circuit passes through the test section. A $50 \mathrm{~mm}$ wide slot just downstream of the test glass draws air back into the demist circuit (through 7). This arrangement provides steady temperature control with only a small amount of overall heat lost to the glass and interior surroundings.

The test glass sample is $7 \mathrm{~mm}$ thick, constructed from laminated flat windshield glass. Housed in a recessed frame, the glass can be easily removed for cleaning and attaching thermocouples. The conditions either side of the glass are monitored using combined temperature and humidity probes in each plenum and thermocouples attached to the corners of each glass surface. Commissioning work provided charts of fan speed vs. mean flow velocity. All data, image acquisition and fan speeds are controlled and processed with a PC.

in a light-sealed box mounted on the door of the test section (8 in Figure 1). Directed through a sample of electrically heated glass, to prevent misting, the camera is focused on a high-contrast chequered background on the surface of the insulated light box. Altering the back focus, positioning and sample size of the camera, the image is set-up to sample only the glass area and no frame or test section wall.

The light box provides uniform back lighting of the glass and has a double-skin surface with a $20 \mathrm{~mm}$ air gap to ensure minimal heating of the cold exterior air from the lamps and reduce the chance of condensation on the light-side surface of the diffusing acrylic. A chequered pattern of black vinyl squares has been applied to the light box to provide a high-contrast background for measuring the intensity and position of misting [12].

Flow measurements using a five-hole pressure probe and hot-wire anemometer were used to assess the flow quality in the exterior circuit duct and at the outlet of the demist jet. The exterior flow remains attached along the full length of the test glass and provides suitable heat exchanging flow to cause uniform heat loss across the glass surface. Flow field traverses downstream of the demist jet indicate typical free jet velocity distribution, as shown for 40:1 aspect ratio jet in Figure 2. Altering the jet width has no effect on the normalised distribution of velocity. Therefore, comparing different width jets in the performance tests is justified as the flow fields are comparable. Turbulence intensity measurements at the centre of the jet outlet, one jet width downstream, vary between 1.2 and $3.2 \%$, increasing as the overall volume flow rate increases (i.e. with increased jet width and increased velocity).

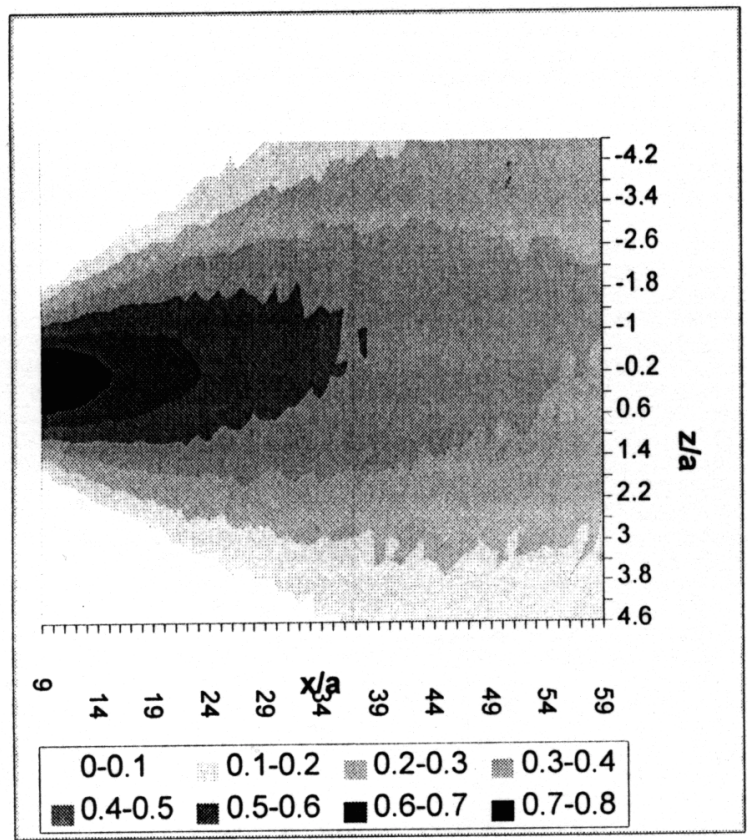

Figure 2. Flow velocity in a horizontal plane downstream of the jet outlet 
Copyright ( 2000 SAE International. This paper is posted on this site with permission from SAE International, and is for viewing only. Further distribution and use of this paper is not permitted withoul permission from $S A E$.

Thermal measurements in the test section indicate that

after a settling period to attain steady temperature, the exterior flow has a typical fluctuation of $+/-0.25 \mathrm{~K}$ due to thermostatic control. This is considered very satisfactory and the surface condensation produced can be considered to provide steady optical distortion.

\section{MIST IMAGING}

Earlier work using greyscale image processing in the 1-D facility studied the distortion in a profile along a horizontal line of pixels from an image of a chequered background lit from above [12]. Examination of mist intensity in vertical planes was not possible due to uneven background lighting. In the 3-D facility, the light box provides uniform lighting across the whole glass surface and thus distortion of single black squares enables an analysis of the 2-D mist distribution.

The imaging technique assesses mist distribution by analysis of up-to-date images taken during testing, which are compared to an image of the glass when completely clear (100\% demisted) and an image when completely misted, usually taken at the start of a test. Previous labour intensive techniques of marking demist contours on the glass surface during cold-room or wax-melt tests[3] are therefore replaced with a much more repeatable method.

The greyscale pixel value, where 0 is black and 255 white for an 8-bit image, at the centre of each black square in the chequered image is extracted from the current, clear and misted images. A non- dimensionalised parameter $(\Psi)$ can then be calculated at each point using the three values, where a value of 1 indicates the glass to be completely clear at that point and a value of 0 indicates misting of the same intensity as at the start of the test.

$$
\Psi=C\left|\frac{I_{\text {current }}-I_{\text {misted }}}{I_{\text {clear }}-I_{\text {misted }}}\right|
$$

Multiplying the parameter by 255 and cubic-spline fitting the points allows construction of a processed image that indicates the exact positioning of demisting. From experience, the image area with a non-dimensionalised parameter value of greater than 0.9 represents the demisted area. By thresholding the processed image at a pixel value of 230 , the resulting binary image defines the area demisted and that still misted. During transient testing, where the glass starts completely misted and eventually demists, the area enclosed within a nondimensional contour value of 0.1 (greyscale value of 26) indicates the area over which demisting can be considered to have been initiated. This is useful in assessing the rate of spreading of the jet across the surface. The post- processing can yield plots of glass area demisted against time for a full range of jet configurations. Commercial processing algorithms can be subsequently applied to the images to measure surface area, bounding coordinates of the demisted area, centre of the demisted area etc. Currently images are taken during tests, stored and post-processed. Images from equivalent repeat tests can be averaged and used in the analysis to improve confidence in the acquired data.

\section{JET PERFORMANCE}

When the jet is used to demist a completely misted sample of glass, the test is considered transient and representative of start-up on a cold, damp morning. If the demist jet is switched on and left to attain thermal equilibrium with the surroundings and for example the interior humidity is increased and the demisted area of glass reduces, this is considered a steady state case. This is more representative of a warm dry cabin, where rain-soaked passengers are in the car and the windows are steamed up. Initially these cases may seem very similar. But the transient case is much more indicative of the ability of the demist jet to increase the surface temperature of the glass, whereas the steady state case represents the nature of the jet entrainment and dispersion of surrounding water vapour.

To investigate the effects of jet geometry on performance, the transient case was analysed first and all combinations of geometric variables were used with factorial analysis of the effects on performance. Results would then indicate representative geometries that produced different characteristics, which could then be analysed using similar performance parameters in the steady state case.

Four geometric variables were used in the assessment of performance:

- $a$, jet width, the jet outlet dimension in a plane perpendicular to the glass surface and parallel with the jet axis

- $d$, offset, the perpendicular distance from the glass surface to the centre of the jet outlet

- $\alpha$, impingement angle, the included angle between the glass surface and jet axis

- $Q$, mean volume flow rate, the area averaged bulk flow rate from the jet outlet.

There is only a small amount of literature covering both aspects of impinging jet flows and visualization of condensation / evaporation. However, research undertaken purely on wall jets and impinging flows is widely reported, with surface temperature measurements via thermochromic paint or embedded thermocouples. The results from the expanse of work can be reduced into describing characteristic regions in the near-wall flow field induced by impinging jet flows onto planar surfaces. 

stagnant cabin air

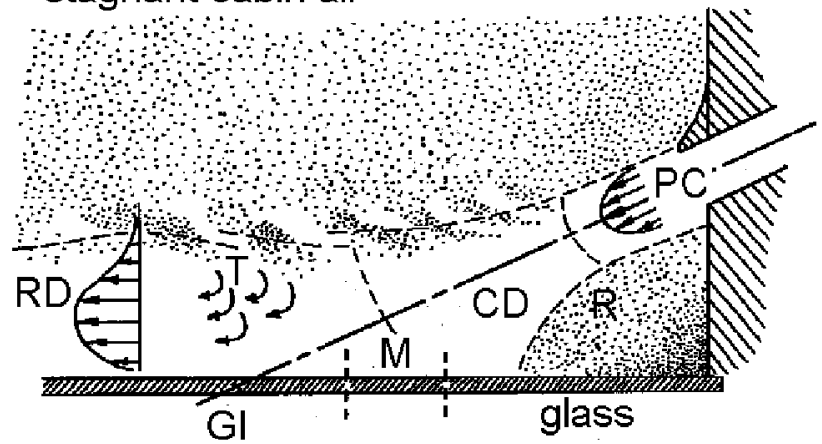

Figure 3. Characteristic flow regions

Firstly, flow visualization tests on simple model defrosters have shown that a recirculation bubble $(\mathrm{R})$ can occur in the triangle formed between the glass, jet and top of the dashboard, which can increase in size as the offset is increased [6].

From work using sublimation mass transfer from napthalene blocks, the point of maximum mass transfer (M) can be shown to be upstream of the geometric impingement point (GI), when a block is exposed to an obliquely impinging airstream [13][14]. Indeed, for zero impingement angle (offset wall jets), the flow attachment point to the wall, described by the Coanda effect, yields the highest heat transfer rates [15]. Upstream of the attachment point a recirculation region is induced.

As heat and mass transfer are analogous, from this evidence it would be expected that the breakthrough point during demisting is upstream of the geometric impingement point. The recirculation region may also affect the demist performance, although whether it enhances or hinders demisting depends on the air entrained into the bubble, either warmer drier demist flow or surrounding cooler damper cabin air.

Along the axis of a 3-D tangential wall jet, 3 distinct regions can be defined [16]. Immediately downstream of the outlet is the potential core region (PC), where the maximum velocity at the jet centre remains constant for up to 4 jet widths downstream. Only the very outer parts of the jet are affected by turbulent shear. Further downstream, the flow can be described by a characteristic decay region (CD), where turbulent shear has penetrated the rectangular jet in the narrow axis and not in the longer wall parallel axis. The geometry of the outlet becomes important here and defines the length of this region. When all the flow has been disturbed by the shear layer surrounding the jet, the flow enters the radial decay region (RD). This produces a similar velocity profile to the wall jet produced by the radial spread of fluid from normal impingement of jets on surfaces [17][18].

Distortions occur in the flow regions depending on the geometry. The distinct CD region of a wall jet may disappear completely, particularly at small offset values, where impingement may occur in the $\mathrm{PC}$ region and after transition ( $T$ ), the $R D$ region may form immediately downstream. For larger offset values, the RD region may not occur at all as flow separates from the top of the glass, disperses into the passenger compartment and demisting will be dominated in the $\mathrm{M}$ and $\mathrm{T}$ regions.

\section{TRANSIENT PERFORMANCE}

To assess transient performance four performance parameters were devised:

- $t_{10 \%}$, the time taken to clear $10 \%$ of the glass area

- $t_{\mathrm{b}}$, the time taken to breakthrough

- $x_{\mathrm{cb}}$, the streamwise coordinate of the breakthrough point

- $A_{\mathrm{b} 0.1}$, the area of glass around the breakthrough point where demisting can be considered to have been initiated

The first performance parameter has been calculated when the area within the 0.9 contour from the processed image equals $10 \%$ of the overall glass area. Singularly, it best represents the transient performance of a demist jet. The position of breakthrough has been referenced to the Gl position calculated from the jet geometry. This parameter indicates the usefulness of a jet geometry in clearing particular areas on the windshield, as regulations determine areas at which demisters must clear within specific times. Breakthrough in this case is defined as the point at which the area enclosed in the 0.9 contour of the processed images equals $1 \%$ of the glass area. $A_{\mathrm{b} 0.1}$ describes the ability of the jet to distribute warm air flow across the glass surface. Some geometries may produce fast breakthrough times, but give up all their energy at impingement and not cause demisting further away. Therefore, $A_{\mathrm{b} 0.1}$ indicates the wider clearing performance of a particular jet geometry.

Table 1. Independent factor levels

\begin{tabular}{llll}
\hline $\mathrm{a}(\mathrm{mm})$ & $\mathrm{Q}(\mathrm{I} / \mathrm{s})$ & $\alpha\left(^{\circ}\right)$ & $\mathrm{d}(\mathrm{mm})$ \\
\hline 5 & 4 & 10 & 40 \\
& 8 & & 120 \\
10 & 4 & 20 & 40 \\
& 8 & & 120 \\
& 16 & & 200 \\
20 & 8 & 40 & 120 \\
& 16 & & 200 \\
\hline
\end{tabular}

Table 1 shows the geometric levels tested. Constraints were applied to produce impingement on the glass surface and reduce test time. A test matrix of 2 and 3 levels was derived and as a result only the linear effects were studied, as quadratic effects may have been extrapolations under certain combinations. The mixed level matrix produced 49 tests, with three levels of offset and volume flow rate for the centre two levels of impingement angle and jet width respectively. 
Copyright @ 2000 SAE International. This paper is posted on this site with permission from SAE International, and is for viewing only. Further distribution and use of this paper is not permitted withoul permission from $S A E$.

Analysis of each jet performance parameter yields 10 linear effects and interactions. Significant effects were taken as those with probability values ( $p$-values) of less than 0.1 and very significant effects with values less than 0.05. To emphasise the significant effects further, the 5 worst effects were pooled into the error estimate.

All 49 test configurations were repeated 8 times and glass was cleaned after every 4 tests. Surface contamination in earlier work proved disruptive in measuring transient performance and clean glass was required throughout [12]. Each test was conducted at the same environmental condition. Table 2 shows the ambient temperatures and velocities used to produce surface condensation. During demisting the interior air supply was turned off. Time histories of images and conditions were collected throughout demisting. Images from the 8 repeats were averaged at the same time interval from start of demisting to produce confident measures of the performance parameters.

Table 2. Ambient test conditions

\begin{tabular}{cccccccc}
\hline & $\begin{array}{c}\mathrm{T}_{\mathrm{e}} \\
\left({ }^{\circ} \mathrm{C}\right)\end{array}$ & $\begin{array}{c}\mathrm{T}_{\mathrm{l}} \\
\left({ }^{\circ} \mathrm{C}\right)\end{array}$ & $\begin{array}{c}\phi_{\mathrm{I}} \\
\left(\% \%_{\mathrm{rh}}\right)\end{array}$ & $\begin{array}{c}\mathrm{T}_{\mathrm{d}} \\
\left({ }^{\circ} \mathrm{C}\right)\end{array}$ & $\begin{array}{c}\phi_{\mathrm{d}} \\
\left(\% \%_{\mathrm{rh}}\right)\end{array}$ & $\begin{array}{c}\mathrm{U}_{\mathrm{e}} \\
(\mathrm{m} / \mathrm{s})\end{array}$ & $\begin{array}{c}\mathrm{U}_{\mathrm{I}} \\
(\mathrm{m} / \mathrm{s})\end{array}$ \\
\hline mean & 8.3 & 20.4 & 73.7 & 26.3 & 40.4 & 6.7 & 0.4 \\
\hline
\end{tabular}

Table 3 shows the top three linear effects in order of significance for the four performance parameters. The sign indicates the direction of the effect and all are highly significant apart from the 3rd effect for the first and third parameters which were significant effects.

Table 3. Top 3 geometric effects on each parameter

\begin{tabular}{llll}
\hline & 1st & 2nd & 3rd \\
\hline$t_{10 \%}$ & $(-) Q$ & $(-) \alpha$ & $(+) d$ \\
$t_{b}$ & $(-) Q$ & $(-) \alpha$ & $(+) d$ \\
$x_{c b}$ & $(+) \alpha$ & $(-) d$ & $(+) \alpha X d$ \\
$A_{b 0.1}$ & $(-) d X \alpha$ & $(+) d$ & $(+) Q$ \\
\hline
\end{tabular}

For the jet width range covered, there was no significant effect on the four performance parameters. Jets of different widths, with the same outlet volume flow rates, performed very similarly.

The flow rate has the strongest effect on $t_{10 \%}$ and $t_{\mathrm{b}}$; increasing the flow rate reduces both parameters. However for the other two performance parameters the geometry of the jet axis with respect to the glass surface is the most significant effect. For all the geometries tested $x_{\mathrm{cb}}$ was negative, indicating maximum mass transfer upstream of the geometric impingement point, as $\mathrm{M}$ and Gl show in Figure 3. Increasing the impingement angle and reducing the offset separately, moves the position of breakthrough towards the geometric impingement point. The effect of the impingement angle is stronger and combined increase in impingement and offset moves the breakthrough position in the streamwise direction. However, this combined increase in offset and impingement reduces the area over which demisting initiates at breakthrough, as illustrated by the effects on $A_{\mathrm{b} 0.1}$.

Increasing flow rate in demister outlets may have a strong effect on demister performance, however this also increases electrical loading on the overall vehicle system, if air supply to other vents is kept constant. As the 2nd and 3 rd effects on $t_{10 \%}$ and $t_{\mathrm{b}}$ illustrate, if flow rate cannot be increased, but better demist performance is required, increasing impingement angle and reducing offset may improve clearing times. However, the position of breakthrough may be closer to the instrument panel. Therefore, combined adjustment of the jet geometry would be required to balance the benefits from improving times and increasing the height above the instrument panel at which demisting occurs.

From observation, shallow impinging large offset jets produced horseshoe shaped demisting patterns, far upstream of the GI position. This indicates a 3-D vortex field in the recirculating region of the demister flow. Other geometries, where clearing occurred much nearer the GI position, indicated that the PC or CD regions of the jet flow were more responsible for demisting, producing more elliptic demist shapes.

\section{STEADY STATE PERFORMANCE}

From the test matrix used in the transient performance experiments, three jet geometries have been selected that are considered to produce separate characteristics. The performance of these jets under steady state thermal conditions through a range of interior humidity levels have been considered using a single performance parameter:

- $A_{0.9}$, the percentage area of the glass that is clear.

The jet configurations tested are described in , each with a jet aspect ratio of $20: 1$ and an outlet flow rate of $8 \mathrm{l} / \mathrm{s}$ (17 cfm). A simple plot of the performance parameter against interior humidity level is used to assess the steady state performance of the three jets. The table also shows the mean conditions throughout the experiments on the three jets.

Table 4. Selected demist jet geometries

\begin{tabular}{llll}
\hline name & $\begin{array}{l}\mathrm{D} \\
(\mathrm{mm})\end{array}$ & $\begin{array}{l}\alpha \\
\left(^{\circ}\right)\end{array}$ & character \\
\hline A & 120 & 40 & $\begin{array}{l}\text { fast breakthrough time, suited to } \\
\text { exterior defrost (wiper free-up) }\end{array}$ \\
B & 200 & 20 & $\begin{array}{l}\text { vortex driven demist (horseshoe } \\
\text { pattern) }\end{array}$ \\
C & 40 & 10 & $\begin{array}{l}\text { demist shape elongated in } \\
\text { streamwise direction }\end{array}$ \\
\hline
\end{tabular}


Copyright $\odot 2000$ SAE International. This paper-is posted on this site withpermission from SAE International, and is for viewing only. Further distribution and use of this paper is not permitted withoul permission from $S A E$. The demist jet, exterior and interior air supplies were run at steady thermal conditions for 1 hour prior to the start of the test and conditions were selected so that no condensation occurred prior to testing. During testing the interior humidity was slowly incremented and due to the control of the humidifier on the interior air circuit the humidity fluctuated very slowly. Images were taken during the peaks in humidity and 8 consecutive images were stored, averaged and processed to measure $A_{0.9}$ at that particular mean humidity level and jet configuration. The same non- dimensionalised image processing technique was used with a clear image taken prior to testing and a completely misted image taken at the end of the tests at maximum humidity level.

Table 5. Mean conditions during testing

\begin{tabular}{cccccc}
\hline jet & $\begin{array}{c}\mathrm{T}_{e} \\
\left({ }^{\circ} \mathrm{C}\right)\end{array}$ & $\begin{array}{c}\mathrm{T}_{\mathrm{l}} \\
\left({ }^{\circ} \mathrm{C}\right)\end{array}$ & $\begin{array}{c}\mathrm{T}_{d} \\
\left({ }^{\circ} \mathrm{C}\right)\end{array}$ & $\begin{array}{c}\phi_{d} \\
\left(\% \%_{r h}\right)\end{array}$ & $\begin{array}{c}\mathrm{U}_{e} \\
(\mathrm{~m} / \mathrm{s})\end{array}$ \\
\hline $\mathrm{A}$ & 8.6 & 20.8 & 30.8 & 33.0 & 6.7 \\
$\mathrm{~B}$ & 8.6 & 20.4 & 30.7 & 32.6 & 6.7 \\
$\mathrm{C}$ & 8.4 & 20.2 & 30.9 & 30.9 & 6.7 \\
\hline
\end{tabular}

Figure 4 shows a plot of $A_{0.9}$ against absolute interior humidity for the three jets. At $9 \mathrm{~g} / \mathrm{kg}$ interior humidity, the glass has just started to mist with jet $A$, it is approximately $75 \%$ clear with jet $C$ and is only $60 \%$ clear with jet $B$. Indeed jet $B$ produces the least robust flow to interior humidity and the glass is completely misted by $11.5 \mathrm{~g} / \mathrm{kg}$ humidity. Jet $\mathrm{C}$ is the most robust jet geometry above $11 \mathrm{~g} / \mathrm{kg}$ interior humidity and maintains a demisted area that is $15 \%$ of the overall glass area up to $13.5 \mathrm{~g} / \mathrm{kg}$ interior humidity, which corresponds to $\sim 88 \%$ rh at $20^{\circ} \mathrm{C}$.

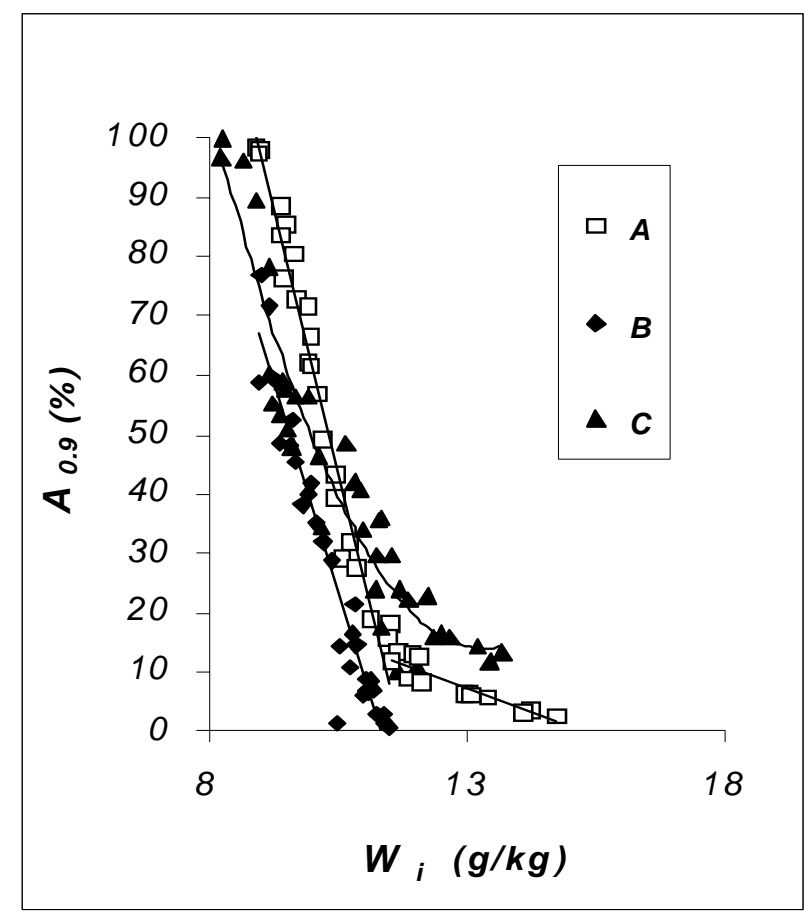

Figure 4. Graph of $A_{0.9}$ against interior absolute humidity
Up to $11 \mathrm{~g} / \mathrm{kg}$ humidity, jet $\mathrm{A}$ is the most robust geometry. However the steep gradient of the linear fit at less than $11.5 \mathrm{~g} / \mathrm{kg}$ indicates the sensitivity of this configuration to interior humidity. Above $11.5 \mathrm{~g} / \mathrm{kg}$, a separate much less inclined fit suits the data. This bi- linear fit suggests a transition in the generated flow field. With reference to Figure 3, the initial linear fit may indicate the progression of the demisted / misted transition line through a RD (radial-type decay) flow region. The second shallow gradient fit suggests that the demisted area is now within a CD / T / M region. Entrainment of surrounding damp fluid in this region would appear to be much less than in the $\mathrm{RD}$ region.

Jet $B$ created horseshoe shaped clearing patterns during the transient experiments. Throughout the steady state tests, jet B maintained elliptical demisted areas and no horseshoe shapes were observed. The fundamental difference between the two experimental methods was the interior flow was switched off in the transient tests, but was set at constant flow rate in the steady state tests.

The horseshoe clearing pattern was generated by a 3- D vortex field in the recirculation region of the flow. Since the interior air flow was turned off in the transient jet tests, the humidity in the test section was non- uniform. Transport of lower humidity air onto the glass surface by the vortices demisted the glass. Therefore, the horseshoe shape was generated by humidity stratification and not rise in surface temperature. In these steady state tests, humid air was continuously supplied to the test section. The demisted area was elliptic, maintained by heat transfer and rise in surface temperature above the dew point.

Jets $A$ and $C$ produced demist patterns that were very similar in shape, both to one another and compared to the transient tests. This suggests the flow is much less 3$\mathrm{D}$ and vortex driven, when compared to jet $\mathrm{B}$. The pattern was independent of humidity stratification. The only differences observed were outside the 0.9 contour. In the transient tests, a 0.1 contour was processed to calculate the area over which demisting had been initiated. In this set of tests, the difference between the clear area and the misted area was much more definite as the surrounding humidity was continuously supplied. Figure 5 illustrates the difference in patterns generated.
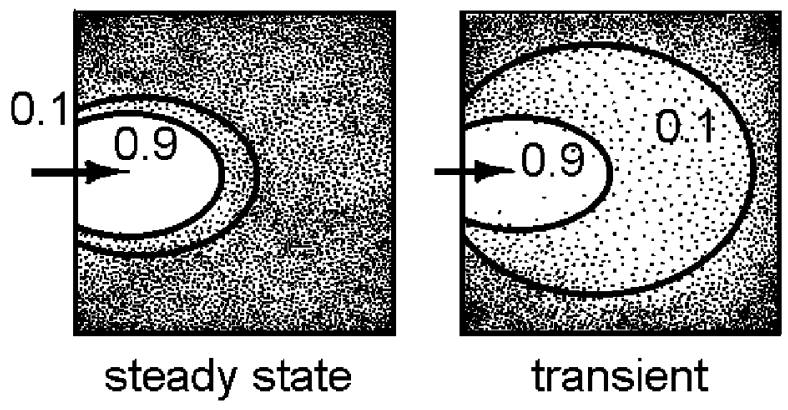

Figure 5. Sketch of the different mist pattern 
Copyright (C) 2000 SAE International. This paper is posted on this site with permission from SAE International, and is for viewing only. Further distribution and use of this paper is not permitted withoul permission from $S A E$.

The right hand sketch in Figure 5 shows the glass during a transient demisting case. The difference between the 0.1 and 0.9 mist contours is much greater, as drier air passes across the glass and initiates clearing over a large area. On the left, humidity is continuously supplied to the surrounding fluid and the contours almost overlay one another. Demisting in this case is much more dependent on the surface temperature generated by the jet heat transfer and downstream warmer flow is infiltrated by surrounding moisture and does not contribute to demisting.

\section{CONCLUSIONS}

A 3-D flow facility has been developed to analyse the effects of demist jet geometry on overall demist performance. Quantitative performance parameters have been created through the use of digital imaging techniques and controlled environmental conditions.

Demister outlet volume flow rate has the strongest effect on time to breakthrough surface condensation and demist the glass over larger areas. However, impingement angle and perpendicular distance of the jet outlet from the base of the windshield also play a significant role in the transient performance and position of breakthrough on the windshield.

Reducing offset and impingement angle together spreads the demister flow across a larger area of the glass. Demisters with shallow impingement and large offset are not robust, as they induce 3-D flow which is much more sensitive to changing surrounding humidity.

Results indicate the need to analyse the flow, surface temperature and local humidity levels to attain a full investigation of the flow field phenomena responsible for robust fast acting demist flows. Flow field measurements of the local velocity, vorticity and turbulence measurements will now be carried out to study demist flow further and improve knowledge of jet performance.

\section{ACKNOWLEDGEMENTS}

This work is supported by Visteon Climate Control Automotive Systems and thanks goes to, Chris Swales and Bashar AbdulNour for their input, direction and backing. Thanks also to the technical staff at Loughborough University for their hard work building the facility.

\section{REFERENCES}

1. Boaz, P., Youngs, J., "Electrically Heatable Windshield and Backlite System", SAE Paper No. 740157

2. Takada, H., "Antifrost System of Windshield", SAE Paper No. 890024
3. Atkinson, W., Muchnij, B., "Wax Method of Determining Windshield Defroster Performance", SAE Paper No. 720504

4. Yamamoto, K., Hill, W., "Interior Flow Visualization of a Small Pick-Up Truck and A/C Feeling Estimate", SAE Paper No. 900082

5. Kohnotou, T., Iwamoto, Y., Hoshiawa, K., Nagataki, M., "Optimum Design of Defroster Nozzle", SAE Paper No. 920167

6. Sakamoto, H., Watanabe, T., Taniguchi, F., "An Analysis of Frost Formation on Vehicle Windows", SAE Paper No. 870028

7. Seban, R., "Heat Transfer and Effectiveness for a Turbulent Boundary Layer with Tangential Fluid Injection", Journal of Heat Transfer, Transactions of ASME, Nov. 1960, pp $303-312$

8. Willenborg, K., Foss, J., AbdulNour, R., McGrath, J., AbdulNour B., "A Model Defroster Flow", 11th Turbulent Shear Flows Symposium, Grenoble, France, Sept. 8 - 11, 1997

9. Baugh, J., Hechanova, A., Yan, X., "An Experimental Study of Entrainment Effects on the Heat Transfer from a Flat Surface to a Heated Circular Impinging Jet", International Journal of Heat and Mass Transfer, Technical Note, v.113, Nov. 1991, pp 1023 - 1025

10. Burch, S., Hassani, V., Penney, T., "Use of Infra- Red Thermography for Automotive Climate Control Analysis", SAE Paper No. 931136

11. Smirnov, V., Verevochkin, G., Brdlick, P., "Heat Transfer Between a Jet and a Held Plater Normal to the Flow", International Journal of Heat and Mass Transfer, v.2, 1961, pp 1 - 7

12. Cole, J., Passmore, M., "An Experimental Study of Automotive Glass Demisting", 2nd MIRA International Conference on Vehicle Aerodynamics, Hilton National Hotel, Coventry, UK, 20 - 21 October, 1998

13. Sparrow, E., Lovell, B., "Heat Transfer Characteristics of an Obliquely Impinging Circular Jet", Journal of Heat Transfer, Transactions of ASME, v.102, May 1980

14. Tien, K., Sparrow, E., "Local Heat Transfer and Fluid Flow Characteristics for Airflow Oblique or Normal to a Square Plate", International Journal of Heat and Mass Transfer, v.22, pp 349 - 360, 1979

15. Kim, D., Yoon, S., Lee, D., Kim, K., "Flow and Heat Transfer Measurements of a Wall Attaching Offset Jet", International Journal of Heat and Mass Transfer, v.39, No. 14, pp 2907 - 2913, 1996

16. Sforza, P., Herbst, G., "A Study of 3-D, Incompressible, Turbulent Wall Jets", AIAA Journal, v.8, No.2, February 1970

17. Bakke, P., "An Experimental Investigation of a Wall Jet", Journal of Fluid Mechanics, v.2, 1957, pp 467 -

18. Glauert, M., "The Wall Jet", Journal of Fluid Mechanics, v.1, 1956, pp 625 - 
Licensed to Loughborough University
Licensed from the SAE Digital Library Copyright 2010 SAE International

Copyright (C) 2000 SAE International. This paper-is posted on this site with permission from SAE International, and is for viewing only. Further distribution and use of this paper is not permitted without permission from $S A E$.

\section{NOMENCLATURE}
A: percentage of glass area
$\%$
a: jet width
$\mathrm{mm}$
C: non-dimensional coefficient
d: offset
$\mathrm{mm}$
I: pixel greyscale value (0 to 255 )
Q: volume flow rate
t: time taken
I/s (dm3/s)
T: temperature
$\mathrm{s}$
U: velocity
C
W: abs humidity (humidity ratio)
$\mathrm{m} / \mathrm{s}$
$\mathbf{x}$ : streamwise coordinate
$\mathrm{g} / \mathrm{kg}$
$\mathrm{mm}$

\section{GREEK}

$\Psi$ : normalised pixel greyscale value $\phi$ : relative humidity

\section{INDICES}

$10 \%$ : relating to $10 \%$ of the glass area

0.1: relating to the 0.1 contour value calculated in the processed image

0.9: relating to the 0.9 contour value calculated in the processed image

b: breakthrough (initial point of demisting)

c: centre

d: demist air supply e: exterior air supply

i: interior air supply 